Original Article

\title{
Dronedarone hydrochloride enhances the bioactivity of endothelial progenitor cells via regulation of the AKT signaling pathway
}

\author{
Jian Zhang ${ }^{1, \#}$, Thi Hong Van Le ${ }^{1, \#}$, Vinoth Kumar Rethineswaran', Yeon-Ju Kim', Woong Bi Jang ${ }^{1}$, Seung Taek Ji', \\ Thanh Truong Giang Ly ${ }^{1}$, Jong Seong Ha ${ }^{1}$, Jisoo Yun ${ }^{1}$, Jae Hun Cheong ${ }^{2}$, Jinsup Jung ${ }^{3, *}$, and Sang-Mo Kwon ${ }^{1,3, *}$
}

\begin{abstract}
'Laboratory for Vascular Medicine and Stem Cell Biology, Research Institute of Convergence Biomedical Science and Technology, Pusan National University Yangsan Hospital, Yangsan 50612, ${ }^{2}$ Department of Molecular Biology, Pusan National University, Busan 46241, ${ }^{3}$ Department of Physiology, School of Medicine, Pusan National University, Yangsan 50612, Korea
\end{abstract}

\section{ARTICLE INFO}

Received March 23, 2021

Revised July 5, 2021

Accepted July 7, 202

*Correspondence

Sang-Mo Kwon

E-mail: smkwon323@pusan.ac.kr,

Jinsup Jung

E-mail: jsjung@pusan.ac.kr

\section{Key Words}

Akt

Cardiovascular disease

Dronedarone

Endothelial progenitor cells

\#These authors contributed equally to this work.
ABSTRACT Cardiovascular disease (CVD) and its complications are the leading cause of morbidity and mortality in the world. Because of the side effects and incomplete recovery from current therapy, stem cell therapy emerges as a potential therapy for CVD treatment, and endothelial progenitor cell (EPC) is one of the key stem cells used for therapeutic applications. The effect of this therapy required the expansion of EPC function. To enhance the EPC activation, proliferation, and angiogenesis using dronedarone hydrochloride $(\mathrm{DH})$ is the purpose of this study. $\mathrm{DH}$ received approval for atrial fibrillation treatment and its cardiovascular protective effects were already reported. In this study, DH significantly increased EPC proliferation, tube formation, migration, and maintained EPCs surface marker expression. In addition, DH treatment up-regulated the phosphorylation of AKT and reduced the reactive oxygen species production. In summary, the cell priming by $\mathrm{DH}$ considerably improved the functional activity of EPCs, and the use of which might be a novel strategy for CVD treatment.

\section{INTRODUCTION}

Cardiovascular diseases (CVD) are the leading cause of death worldwide [1-3]. Increased incidence of obesity, diabetes and other factors in both developed and developing countries enhances the CVD burden [2]. Although there are many treatment therapies including medications, vascular intervention, surgery, the injured tissue will incompletely recover. Stem cell therapy is considered as a potential therapy for CVD treatment [4].

Angiogenesis is the development the new vessels from current ones. Endothelial progenitor cells (EPCs) were derived from adult peripheral blood [5]. Endothelial cells are present on the inner membrane of the blood vasculature and contribute primarily to the pathological progression of cardiovascular disease. The endothelial cells differentiated from the EPCs contribute to endothelial vasculature formation [6]. EPCs can form new blood vessels via sprouting and intussusception, an essential physiological process [7]. Recent data show EPCs can have important pathophysiological and therapeutic applications in ischemia and atherosclerotic diseases; further, patients with acute myocardial infarction have been known to have increased EPC numbers in the blood, which might be beneficial for such applications $[8,9]$. Our results are (i) \$ This is an Open Access article distributed under the terms of the Creative Commons Attribution Non-Commercial License, which permits unrestricted non-commercial use, distribution, and reproduction in any medium, provided the original work is properly cited. Copyright @ Korean J Physiol Pharmacol, pISSN 1226-4512, eISSN 2093-3827
Author contributions: J.Z. and T.H.V.L. designed the project, established the experimental protocols and wrote the main manuscript text, and Y.J.K., W.B.J., S.T.J., V.K.R., T.T.G.L., J.S.H., J.S.Y., and J.H.C. prepared the figures and contributed to the statistical analyses. All authors reviewed the manuscript. J.S.J. and S.M.K. supervised the entire project. J.Z. and T.H.V.L. contributed equally in this manuscript. 
similar to those of earlier reports on the repair of injured tissues after EPC transplantation in the hind limb ischemia model [10].

Dronedarone hydrochloride (DH), an alternative to amiodarone, is a multichannel blocking antiarrhythmic drug for atrial fibrillation (AF) and atrial flutter treatment [11-13]. DH exhibits a protective effect on the microcirculation during treatment of $\mathrm{AF}$ [14], and results showed that during AF, treatment with $\mathrm{DH}$ decreased deaths and first hospitalization because of cardiovascular events $[14,15]$. Surprisingly, to date, studies on the effect of $\mathrm{DH}$ on EPCs are lacking. Therefore, we hypothesize that DH-based cell priming might be beneficial for EPC application for CVD treatment.

Protein kinase B (AKT) is a critical downstream effector molecule of stromal-derived factor 1 and vascular endothelial growth factor (VEGF); it traffics EPCs efficiently into the ischemic muscle, and mediates EPC homing, angiogenesis, and endothelial survival [16]. We have shown the role of extracellular signalregulated kinase (ERK) activation in improving EPC functions [17]. AKT are upstream regulators of target tuberous sclerosis complex (TSC1/2), and after activation, the TSC1/2 inhibits Rheb, further inhibiting the mechanistic target of rapamycin complex 1 [18]. Moreover, our recent studies showed the role of AKT/mTOR signaling in EPC growth, proliferation, differentiation, and angiogenesis [19].

Reactive oxygen species (ROS) contribute to the pathogenesis of various diseases, including diabetes, acute ischemia, atherosclerosis. ROS function as secondary intracellular messengers and regulate the total redox that controls the apoptosis, proliferation, self-renewal, senescence, and differentiation [20,21]. ROS play a crucial role in EPC function maintenance [22]. High ROS production leads to EPC dysfunction.

This study aimed to explore the beneficial effects of $\mathrm{DH}$ on EPC molecular mechanisms and vascular characteristics.

\section{METHODS}

\section{Isolation and culture of EPCs}

Human umbilical cord blood from healthy volunteers according to the protocol approved by the Institutional Review Board of Pusan National University Yangsan Campus Hospital (approval no. PNUYH-05-2017-053). All volunteers who had samples taken had provided informed consent. The present study was approved by the ethics committee of the Yangsan Hospital of Pusan National University and was performed in accordance with the declaration of Helsinki. Mononuclear cells (MNCs) from the human umbilical cord blood were isolated by density gradient centrifugation using ficoll (GE Healthcare, Buckinghamshire, UK). After isolation, MNCs were seeded on $1 \%$ gelatin-coated culture plates and maintained in endothelial growth medium-2 (EGM-2) (Lonza, Walkersville, MD, USA) containing endothelial basal medium-2 with 5\% fetal bovine serum (FBS), $1 \%$ penicillinstreptomycin, human VEGF, human basic fibroblast growth factor, human insulin-like growth factor-1, human epidermal growth factor, ascorbic acid, and GA-1000. The medium was changed every day, and the colonies were cultured further for experimental use. EPC cells from passages 4 to 13 were used in the experiments.

\section{Cytotoxicity assay}

The cell cytotoxicity assays were conducted using D-Plus CCK8 (CCK-8-Dongin LS, Seoul, Korea). Before seeding cells, each 96well plate was coated with $1 \%$ gelatin (Sigma, St. Louis, MO, USA) dissolved in $1 \times$ phosphate-buffered saline (PBS), incubated for at least $15 \mathrm{~min}$ in a $\mathrm{CO}_{2}$ incubator and washed once with $1 \times \mathrm{PBS}$. After removing the gelatin, 5,000 cells were seeded per well and incubated overnight. The spent media were replaced with fresh media containing DMSO, DH (Sigma), DH plus $5 \mu \mathrm{M}$ AKT inhibitor (Sigma) and incubated for $24 \mathrm{~h}, 48 \mathrm{~h}$. After that, the media were aspirated, and a diluted CCK- 8 solution (a 10:1 ratio of media to CCK-8 solution) was added to each well and incubated for $2 \mathrm{~h}$ in a $\mathrm{CO}_{2}$ incubator. The absorbance at $450 \mathrm{~nm}$ was measured using a microplate reader (Tecan XFluor, Mannedorf, Switzerland).

\section{Tube formation assay (in vitro angiogenesis)}

For the in vitro tube formation assay, 96-well plates coated with matrigel GFR (BD Biosciences, San Jose, CA, USA) were incubated in a $\mathrm{CO}_{2}$ incubator for $30 \mathrm{~min}$, and 6,000 cells/well with or without $\mathrm{DH}$ were seeded and incubated for $6-12 \mathrm{~h}$. The cell tube formation ability was determined by counting the number of tubes formed and measuring the total length of the tubes formed using a microscope (Olympus, Tokyo, Japan). Images were captured in one microscopic field per well under $40 \times$ magnification. Scar bar: $200 \mu \mathrm{m}$.

\section{Western blot analysis}

Total protein was extracted with pro-prep for $30 \mathrm{~min}$ on ice and vortexed for $5 \mathrm{~s}$ every $5 \mathrm{~min}$. The supernatant was collected and the protein concentration was determined using a bicinchoninic acid kit (Thermo Fisher Scientific, Rockford, IL, USA). Proteins were separated by $8 \%-10 \%$ sodium dodecyl sulfatepolyacrylamide gel electrophoresis and transferred to immobilon polyvinylidene fluoride membranes (Millipore, Billerica, MA, USA). The membranes were blocked with $5 \%$ skim milk at room temperature for $1 \mathrm{~h}$, and incubated with primary antibodies against AKT, p-AKT (S473) (Cell signaling technology, Boston, MA, USA), $\beta$-actin (Santa Cruz Biotechnology, Dallas, TX, USA) at $4^{\circ} \mathrm{C}$ overnight. After removing the primary antibody, the membranes were washed with $1 \times$ Tris-buffered saline containing $0.1 \%$ Tween 20 (TBST) for $1 \mathrm{~h}$. The membranes were incubated with 
secondary antibodies at room temperature for $1 \mathrm{~h}$. Anti-rabbit horseradish peroxidase (HRP) conjugate and anti-mouse HRP conjugate (Enzo Life Sciences, Farmingdale, NY, USA) were used as secondary antibodies. After washing the membranes again with $1 \times$ TBST for $1 \mathrm{~h}$, the bands were visualized using immobilon crescendo western HRP substrate (Immobilon; Millipore) and Xray film. $\beta$-Actin was used as the loading control for Western blot results.

\section{Scratch wound healing assay}

Cells $\left(2 \times 10^{5}\right.$ cells/well) were seeded on a 6-well plate and cultured to $90 \%$ confluence (about two days). Cells were scratched using a $200 \mu \mathrm{l}$ pipet tip and washed twice with PBS. Next, the cells were incubated in complete medium with or without $\mathrm{DH}$ and the $\mathrm{AKT}$ inhibitor for $6 \mathrm{~h}$ at $37^{\circ} \mathrm{C}$ in a $\mathrm{CO}_{2}$ incubator. Images were captured using a light microscope (Olympus). The wound healing area was measured using ImageJ software (NIH, Bethesda, $\mathrm{MD}$, USA). Cell migration activity was calculated as the migration area: [(initial scratch area $\mathrm{A}_{0 \mathrm{~h}}$ - final scratch area $\mathrm{A}_{6 \mathrm{~h}}$ ) / initial scratch area $\left.\left.\mathrm{A}_{0 \mathrm{~h}}\right) \times 100 \%\right]$. Scar bar: $200 \mu \mathrm{m}$.

\section{Transwell migration assay}

Transwell migration assays were performed using 24-well Transwell inserts ( $8 \mu \mathrm{M}$ pore size; Costar, Columbia, WA, USA). In each upper insert, $2 \times 10^{4}$ cells were seeded in $100 \mu \mathrm{l}$ of EGM2; EGM-2 containing 2\% FBS was placed in each lower chamber and incubated at $37^{\circ} \mathrm{C}$ for $6 \mathrm{~h}$. Later, cells were fixed for $10 \mathrm{~min}$ utes in $4 \%$ paraformaldehyde and stained for 30 min with $0.5 \%$ crystal violet (25\% methanol and $1 \%$ crystal violet at a ratio of $1: 1)$.
The inserts were washed twice with distilled water until clean, and the membranes were excised and mounted on glass slides. The cell migratory ability was quantified by counting the number of migrated cells in three random microscopic fields ( $4 \times$ magnification) using a Lion Heart FX automated microscope (Biotek, Winooski, VT, USA). Scar bar: $1,000 \mu \mathrm{m}$.

\section{Flow cytometry analysis}

Pretreated cells were identified and characterized by flow cytometry using hematopoietic stem cell markers CD34, c-kit, CXCR4, Tie2, CD31, and CD144 (BD Pharmingen, Franklin Lake, NJ, USA). FACS gating was applied using unstained cells as a negative control. The flow cytometry analysis was carried out by fluorescence-activated cell sorting (FACS; BD FACS canto 2, San Joes, CA, USA). The percentage of stained cells was shown as red peaks.

\section{Carboxy-H2DFFDA assay}

ROS production was evaluated using a carboxy-H2DFFDA probe (Life Technologies, Carlsbad, CA, USA). Cells were incubated with $1 \mu \mathrm{M}$ carboxy-H2DFFDA at $37^{\circ} \mathrm{C}$ for $20 \mathrm{~min}$ in the dark and washed twice with PBS. Next, the cells were collected and analyzed by FACS (BD Biosciences). Total cellular ROS levels were expressed as the average DCF fluorescence intensity of the cells.

\section{Statistical analysis}

Statistical analyses were performed using the GraphPad Prism
A
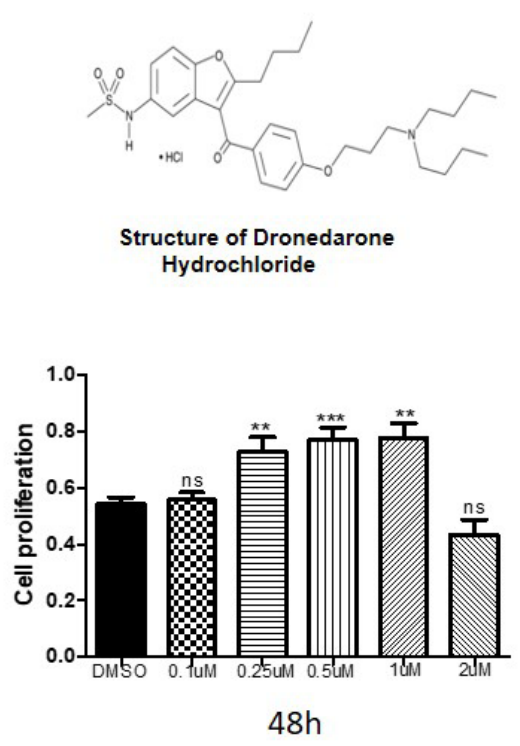

B

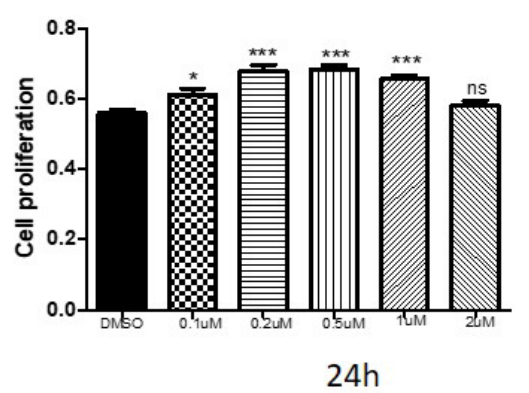

C

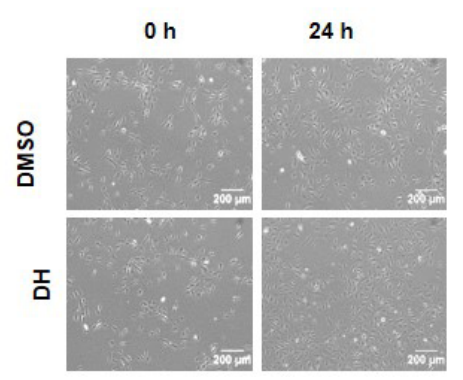

Fig. 1. Effect of DH on EPC proliferation. (A) The chemical structure of $\mathrm{DH}$. (B) EPCs were cultured with varying concentrations of $\mathrm{DH}$ for $24 \mathrm{~h}, 48 \mathrm{~h}$ and cell proliferation assessed by the CCK-8 assay. (C) EPC morphology during treatment with $\mathrm{DH}$. Data represent the mean \pm SEM. DH, dronedarone hydrochloride; EPC, endothelial progenitor cell. The results are considered statistically significant at ${ }^{*} \mathrm{p}<0.05,{ }^{* *} \mathrm{p}<0.01,{ }^{* * *} \mathrm{p}<0.001$ when compared to untreated groups. 
software version 5 (GraphPad Software Inc., San Diego, CA, USA). Data are presented as mean \pm standard error of the mean (SEM). Data were analyzed by the Student's t-test. The p-values were designated as follows: ${ }^{*} \mathrm{p}<0.05,{ }^{* *} \mathrm{p}<0.01,{ }^{* * *} \mathrm{p}<0.001$. The experimental data presented were an average of three independent experiments.

\section{RESULTS}

\section{Effect of DH on EPC proliferation}

This study aimed to evaluate DH activity on EPC bioactivities. The chemical structure of DH is shown in Fig. 1A. DH significantly improved cell proliferation in a dose-dependent manner $(0.1,0.2,0.5,1,2 \mu \mathrm{M})$ for $24 \mathrm{~h}$ and $48 \mathrm{~h}$. (Fig. 1B). DH did not change the morphology of EPCs (Fig. 1C).

\section{Characterization of EPCs}

EPC and endothelial cells (ECs) surface markers are important for evaluating endothelial function. We confirmed the effect of $24 \mathrm{~h}$ treatment with $0.5 \mu \mathrm{M} \mathrm{DH}$ on endothelial functional activation, and the surface markers of EPCs and ECs were evaluated by flow cytometry analysis (Fig. 2). There is no significant difference in the expression of cell surface markers between the two groups.

\section{Priming of DH enhances the angiogenic activity in EPCs}

EPCs play a crucial role in angiogenesis, and angiogenesis is believed to be a vital indicator of EPC function. The effect of $\mathrm{DH}$ on in vitro cell tube formation was assessed. For tube formation assay, cells were treated with $\mathrm{DH}(0.5 \mu \mathrm{M})$ for $12 \mathrm{~h}$ and $\mathrm{DH}$ treated cells displayed significantly enhanced tubular networks and branch points (Fig. 3B, C). Along with the tube formation ability, mobilization and homing abilities are also important indicators of EPC functionality. For evaluating the effect of DH on cell migratory ability, the scratch wound healing assay (Fig. 3D, F) and transwell migration assay (Fig. 3E, G) were performed. Results showed that $\mathrm{DH}$ treatment significantly increased scratch wound healing and transwell migration.

\section{Priming of DH regulates AKT signaling and ROS reduction in EPCs}

Previously, we confirmed the role of AKT/mTOR and ERK signaling in EPC functionality [17,19]. Therefore, to elucidate the underlying mechanism of the DH effect on enhancing EPC function, cells were treated with or without $\mathrm{DH}(0.5 \mu \mathrm{M})$ for $24 \mathrm{~h}$, and the phosphorylation of AKT and its total form expression were assessed by Western blotting. Compared with the control group, $\mathrm{DH}$ significantly increased the expression of phosphor-AKT in
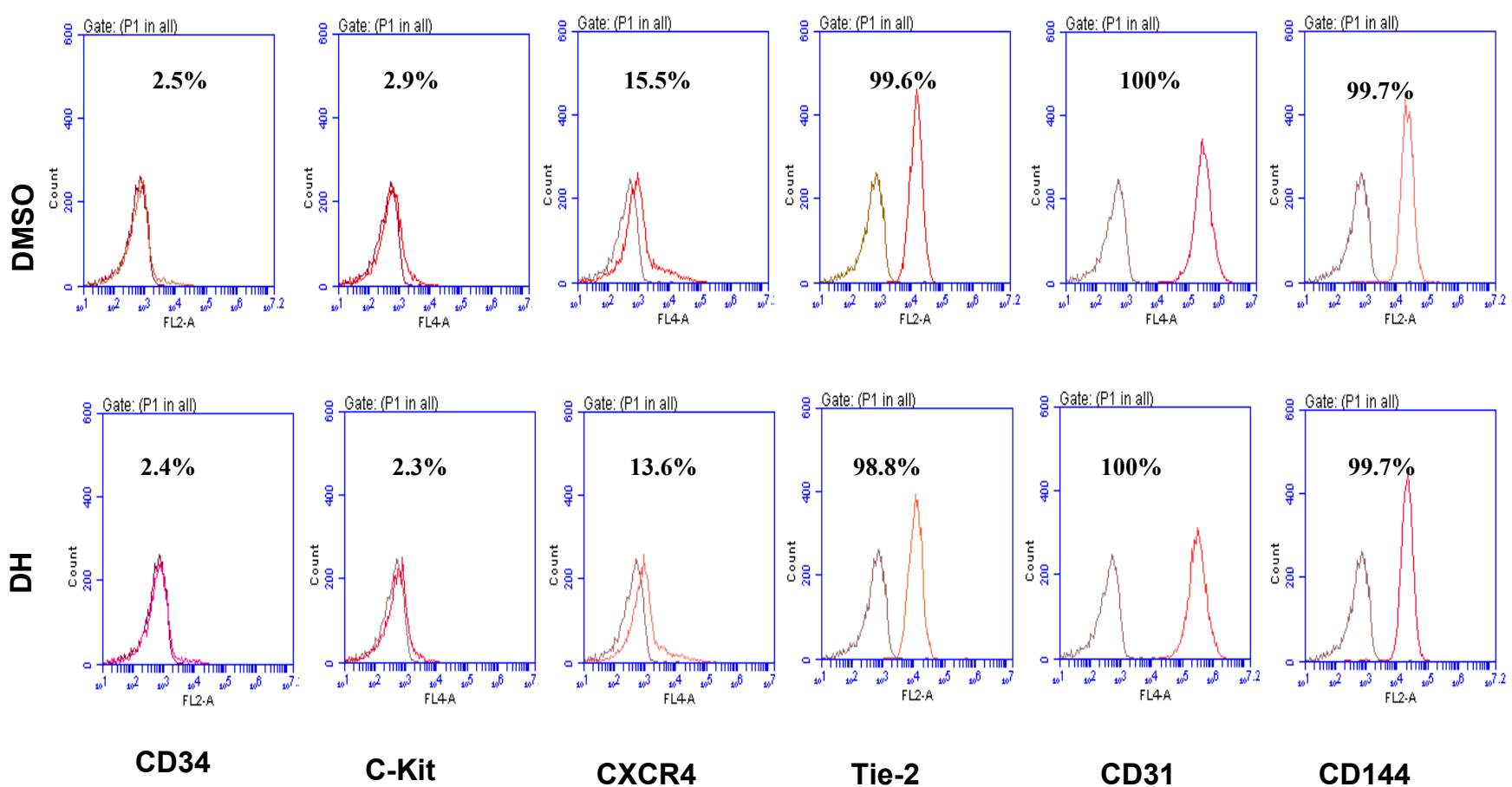

Tie-2

CD31

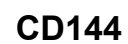

Fig. 2. Characterization of endothelial functional activation by EPC and EC surface markers. The expression of EPC (CD34, C-kit, CXCR4) and EC (Tie2, CD31, CD144) surface markers were analyzed by flow cytometry, and no significant differences were observed. FACS gating was applied using unstained cells as a negative control. The fraction of positively stained cells was determined by comparison with unstained cells. The percentage of positively stained cells is indicated by the positive peaks (red lines show cells stained with each antibody, and black lines show the negative control cells). EPC, endothelial progenitor cell; EC, endothelial cell; FACS, fluorescence-activated cell sorting. 
A

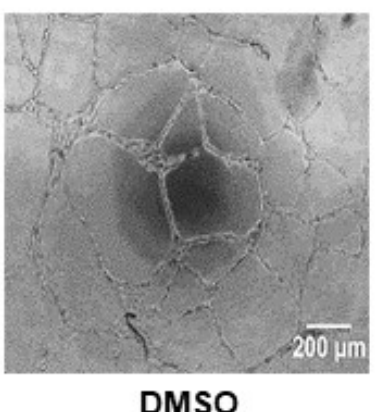

D $\quad 0 \mathrm{~h}$
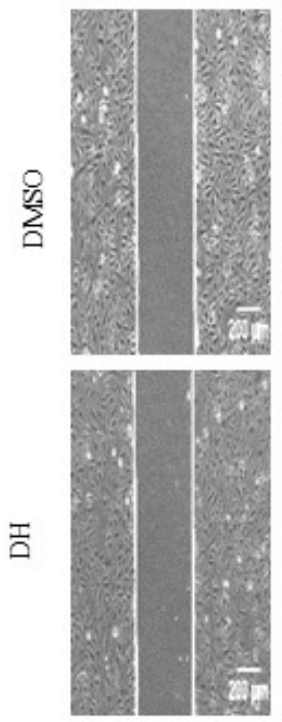

$6 \mathrm{~h}$

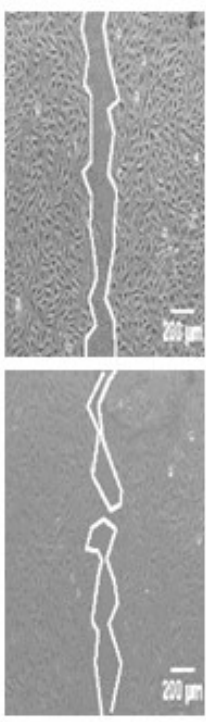

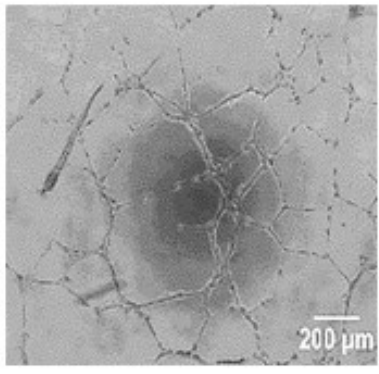

DH
B

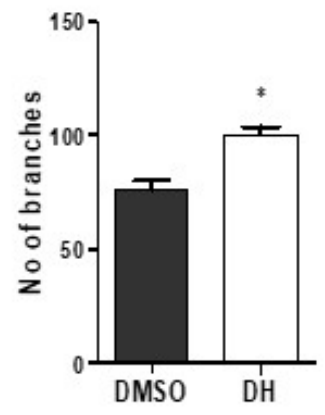

C

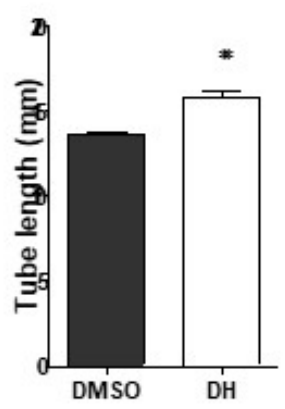

E
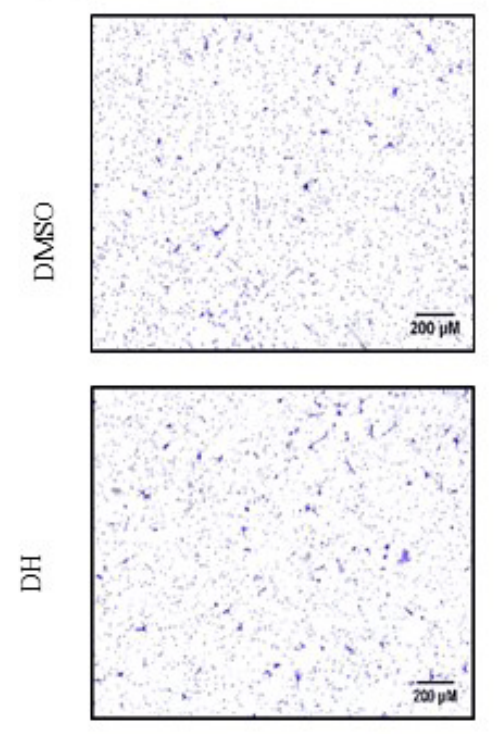

$\mathbf{F}$

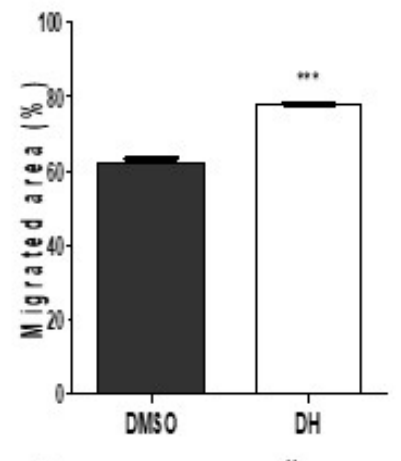

G

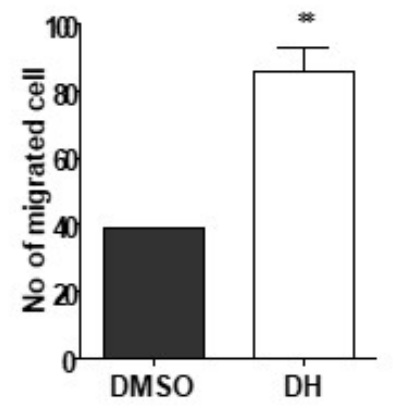

Fig. 3. DH enhances EPC functional ability. (A) EPCs treated with or without $\mathrm{DH}(0.5 \mu \mathrm{M})$ were seeded on matrigel-coated wells and the angiogenic function was evaluated in a tube formation assay. Representative images of tube formation (40X). (B, C) Quantification of the number of branches and length. (D, E) Representative images of the scratch wound healing and migration assay. $(F, G)$ Quantification of the migrated area and number of migrated cells. Data represent the mean \pm SEM. DH, dronedarone hydrochloride; EPC, endothelial progenitor cell. The results are considered statistically significant at ${ }^{*} p<0.05,{ }^{* *} p<0.01,{ }^{* * *} p<0.001$ when compared to untreated groups.

dose-dependent manner (Fig. 4A, B). DH in the combination with AKT inhibitor inhibited the phosphor-AKT expression in Western blot (Fig. 4C, D). To determine whether AKT signaling plays the role in $\mathrm{DH}$ enhances the proliferation, wound healing. Treatment of cells with $\mathrm{DH}(0.5 \mu \mathrm{M})$ in combination with AKT inhibitor $(5 \mu \mathrm{M})$ blocked cell proliferation, wounding healing (Fig. 4E, F, and G). Optimal ROS production play a crucial role in physiological activities, increased production of ROS lead to the EPC dysfunction that exhibits the reduction of proliferation, migration. Our data showed that $\mathrm{DH}$ reduced significantly the ROS production (Fig. 4H, I).

\section{DISCUSSION}

Asahara et al. [5] that is the first scientist isolated successful
EPCs. Characteristics and function of EPCs are more knowledgeable. EPCs can form new blood vessels [23]. EPCs are released from the bone marrow into circulating blood during vascular damage [24]. After differentiation, the mature endothelial cells play a vital role in the repair of blood vessels [25]. EPC proliferation, tube formation, and ability to migratory reflect their health [26].

The incidence of cardiovascular diseases continuously increasing due to the aging population, metabolism diseases increasing. Stem cell transplantation is a therapeutic potential therapy against ischemic diseases. The effect of this therapy required the improvement of EPC functions. This study aimed to investigate the effect of the US Food and Drug Administration-approved drug DH on human EPC bioactivity. Previous reports showed the effect of DH on CVD and hospitalization for cardiovascular events during AF treatment [15]. We hypothesize that $\mathrm{DH}$ might 
A

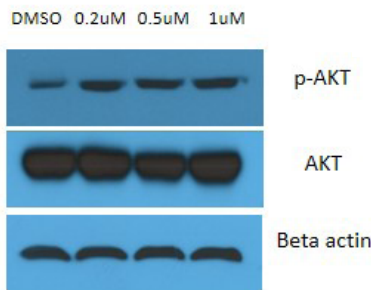

E

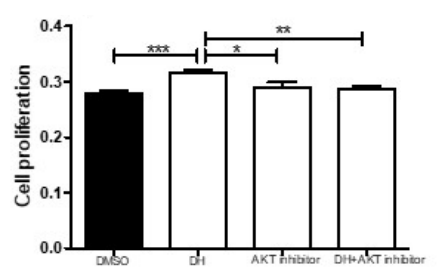

$24 \mathrm{~h}$
B

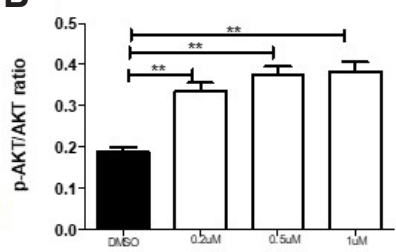

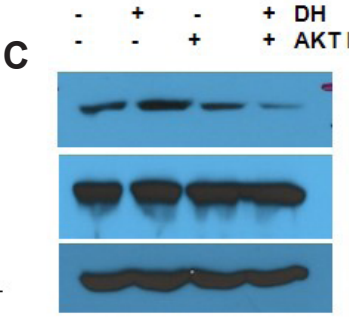

$\mathbf{F}$

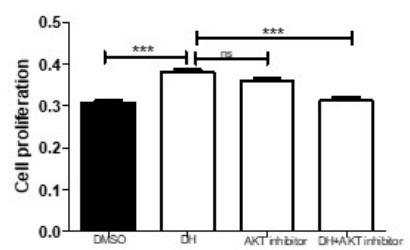

$48 \mathrm{~h}$

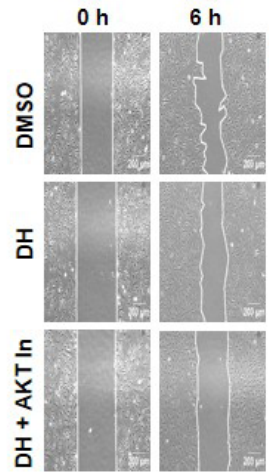

H
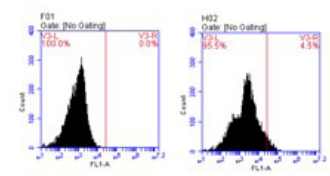

Non-staining DMSO

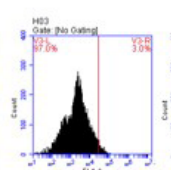

$\mathrm{DH}$

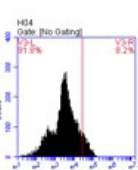

AKT inhibitor

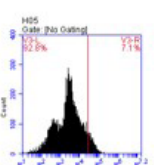

UH+ AKI Innibitor

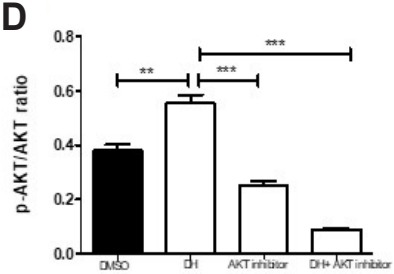

G

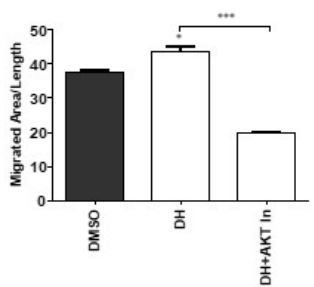

I

Fig. 4. DH enhances angiogenic activity by regulating AKT signaling. (A) Protein level expression of AKT and its phosphorylation was evaluated by Western blotting in dose dependent-manner of DH. (B) Quantification of Western blots. (C) Protein level expression of AKT and its phosphorylation was evaluated by Western blots. EPCs were cultured with DMSO, DH, and DH plus AKT inhibitor (5 $\mu \mathrm{M})$. (D) Quantification of Western blots. (E) Cell treated with $\mathrm{DH}(0.5 \mu \mathrm{M})$ and in the combination with AKT inhibitor $(5 \mu \mathrm{M})$ for $24 \mathrm{~h}$ then proliferation was measured. Scratch wound healing assay was performed to measure wound healing properties and cell migration was measured with the Image J software (NIH, Bethesda, MD, USA). (F) Representative images of the scratch wound healing assay. $(\mathrm{H})$ Carboxy-H2DFFDA was used to measure ROS production. Cells were pretreated with DH with or without AKT inhibitor then ROS was measured by FACS. (I) Quantification of ROS production. Data represent the mean \pm SEM. DH, dronedarone hydrochloride; EPC, endothelial progenitor cell; ROS, reactive oxygen species; FACS, fluorescence-activated cell sorting. The results are considered statistically significant at ${ }^{*} p<0.05,{ }^{* *} p<0.01,{ }^{* * *} p<0.001$ when compared to untreated groups.

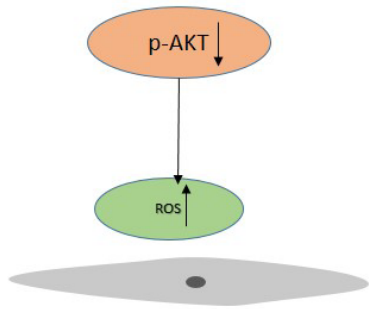

EPC dysfunction, apoptosis

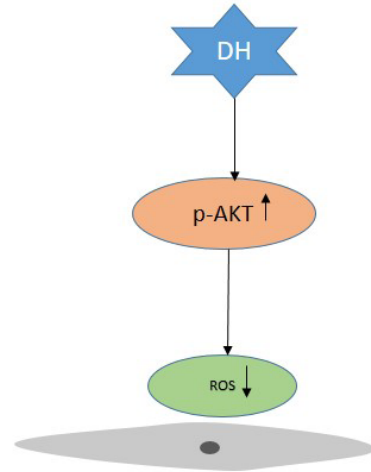

EPC Proliferation, survival, migration and angiogenesis $\uparrow \uparrow \uparrow$
Fig. 5. Schematic diagram representation of DH enhance the angiogenic activity via AKT signaling. Exposure of $\mathrm{DH}$ up-regulate the expression of $\mathrm{p}-\mathrm{AKT}$, ROS reduction lead to the improvements of EPC function. $\mathrm{DH}$, dronedarone hydrochloride; EPC, endothelial progenitor cell; ROS, reactive oxygen species. enrich functional EPC activity. Our results validated the hypothesis and showed the stimulatory effect of DH on EPC proliferation, tube formation, and cell migration (Figs. 1, 3, 4). So priming with DH may enhance the functional of EPCs.

The EPC (CD34, c-kit, and CXCR4) and EC surface markers (Tie2, CD31, and CD144) play important roles in endothelial functional activity. Our results clearly demonstrated that $\mathrm{DH}$ did not affect cell morphology (Fig. 1C), or typical EPC and EC surface markers (Fig. 2). Therefore, these data suggest that $\mathrm{DH}$ primed EPCs are not altered significantly, thus indicating the safety of DH for priming EPCs.

$\mathrm{AKT}$ is a serine/threonine-specific protein kinase implicated 
in a variety of cellular functions, such as cell proliferation, cell migration, and angiogenesis. Phosphorylation of AKT leads to P70S6K phosphorylation to further activate protein synthesis, and eNOS phosphorylation increases nitric oxide release, a critical regulator of EPC angiogenesis and migration. Priming with $\mathrm{DH}$ enhances the phosphor-AKT expression in dose-dependent manner. We also determine that $\mathrm{DH}$ in the combination with AKT inhibitor dramatically reduces the phosphor-AKT expression (Fig. 4A-D). We showed that inhibition of AKT negatively regulated cell proliferation, wound healing (Fig. 4E, F).

Excessive ROS production was observed in various diseases condition such as diabetes, ischemia, atherosclerosis that results in EPC dysfunction [27]. We also showed that priming with $\mathrm{DH}$ reduced significantly the ROS production in EPCs (Fig. 4H, I). It suggested the protective role of DH in EPCs function.

Our study showed that priming of DH is a promising therapeutic strategy to enhance the EPCs functions via regulation of the AKT signaling pathway. The effect of DH in EPC bioactivities was illustrated in Fig. 5.

\section{ACKNOWLEDGEMENTS}

This work was supported by a grant from the National Research Foundation (NRF-2015R1A5A2009656 and 2018R1A2B6007478), Korean Health Technology R\&D Project, Ministry of Health and Welfare (HI18C2459); the Technology innovation Program (No. 20000325, Development of tissue engineered blood vessels using tissue specific bioink and 3D printing technique) funded by the Ministry of Trade, Industry \& Energy (MOTIE, Korea); and was funded by the Korean government.

\section{CONFLICTS OF INTEREST}

The authors declare no conflicts of interest.

\section{REFERENCES}

1. Cully M. Cardiovascular disease: BET inhibitor attenuates heart failure. Nat Rev Drug Discov. 2017;16:453.

2. Dimmeler S. Cardiovascular disease review series. EMBO Mol Med. 2011;3:697.

3. Kuehn BM. Sleep duration linked to cardiovascular disease. Circulation. 2019;139:2483-2484.

4. Yoshida Y, Yamanaka S. Recent stem cell advances: induced pluripotent stem cells for disease modeling and stem cell-based regeneration. Circulation. 2010;122:80-87.

5. Asahara T, Murohara T, Sullivan A, Silver M, van der Zee R, Li T, Witzenbichler B, Schatteman G, Isner JM. Isolation of putative progenitor endothelial cells for angiogenesis. Science. 1997;275:964-967.

6. Sen S, McDonald SP, Coates PT, Bonder CS. Endothelial progenitor cells: novel biomarker and promising cell therapy for cardiovascular disease. Clin Sci (Lond). 2011;120:263-283.

7. Zhao T, Li J, Chen AF. MicroRNA-34a induces endothelial progenitor cell senescence and impedes its angiogenesis via suppressing silent information regulator 1. Am J Physiol Endocrinol Metab. 2010;299:E110-E116.

8. Dimmeler S, Burchfield J, Zeiher AM. Cell-based therapy of myocardial infarction. Arterioscler Thromb Vasc Biol. 2008;28:208-216.

9. Shintani S, Murohara T, Ikeda H, Ueno T, Honma T, Katoh A, Sasaki K, Shimada T, Oike Y, Imaizumi T. Mobilization of endothelial progenitor cells in patients with acute myocardial infarction. Circulation. 2001;103:2776-2779.

10. Lee JH, Lee SH, Choi SH, Asahara T, Kwon SM. The sulfated polysaccharide fucoidan rescues senescence of endothelial colonyforming cells for ischemic repair. Stem Cells. 2015;33:1939-1951.

11. Naccarelli GV, Wolbrette DL, Levin V, Samii S, Banchs JE, PennyPeterson E, Gonzalez MD. Safety and efficacy of dronedarone in the treatment of atrial fibrillation/flutter. Clin Med Insights Cardiol. 2011;5:103-119.

12. Sun W, Sarma JS, Singh BN. Electrophysiological effects of dronedarone (SR33589), a noniodinated benzofuran derivative, in the rabbit heart: comparison with amiodarone. Circulation. 1999;100:22762281.

13. Sun W, Sarma JS, Singh BN. Chronic and acute effects of dronedarone on the action potential of rabbit atrial muscle preparations: comparison with amiodarone. J Cardiovasc Pharmacol. 2002;39:677-684.

14. Pisters R, Hohnloser SH, Connolly SJ, Torp-Pedersen C, NaditchBrûlé L, Page RL, Crijns HJ. Effect of dronedarone on clinical end points in patients with atrial fibrillation and coronary heart disease: insights from the ATHENA trial. Europace. 2014;16:174-181.

15. Hohnloser SH, Crijns HJ, van Eickels M, Gaudin C, Page RL, TorpPedersen C, Connolly SJ. Effect of dronedarone on cardiovascular events in atrial fibrillation. N Engl J Med. 2009;360:668-678.

16. Hur J, Yoon CH, Lee CS, Kim TY, Oh IY, Park KW, Kim JH, Lee HS, Kang HJ, Chae IH, Oh BH, Park YB, Kim HS. Akt is a key modulator of endothelial progenitor cell trafficking in ischemic muscle. Stem Cells. 2007;25:1769-1778.

17. Kim YJ, Ji ST, Kim DY, Jung SY, Kang S, Park JH, Jang WB, Yun J, Ha J, Lee DH, Kwon SM. Long-term priming by three small molecules is a promising strategy for enhancing late endothelial progenitor cell bioactivities. Mol Cells. 2018;41:582-590.

18. Laplante M, Sabatini DM. mTOR signaling in growth control and disease. Cell. 2012;149:274-293.

19. Rethineswaran VK, Kim YJ, Jang WB, Ji ST, Kang S, Kim DY, Park JH, Van LTH, Giang LTT, Ha JS, Yun J, Lee DH, Yu SN, Park SG, Ahn SC, Kwon SM. Enzyme-aided extraction of fucoidan by AMG augments the functionality of EPCs through regulation of the AKT/ Rheb signaling pathway. Mar Drugs. 2019;17:392.

20. Adler V, Yin Z, Tew KD, Ronai Z. Role of redox potential and reactive oxygen species in stress signaling. Oncogene. 1999;18:61046111.

21. Lander HM, Milbank AJ, Tauras JM, Hajjar DP, Hempstead BL, Schwartz GD, Kraemer RT, Mirza UA, Chait BT, Burk SC, Quilliam LA. Redox regulation of cell signalling. Nature. 1996;381:380-381.

22. Fleissner F, Thum T. Critical role of the nitric oxide/reactive oxygen species balance in endothelial progenitor dysfunction. Antioxid Re- 
dox Signal. 2011;15:933-948.

23. Kawamoto A, Asahara T, Losordo DW. Transplantation of endothelial progenitor cells for therapeutic neovascularization. Cardiovasc Radiat Med. 2002;3:221-225.

24. Alev C, Ii M, Asahara T. Endothelial progenitor cells: a novel tool for the therapy of ischemic diseases. Antioxid Redox Signal. 2011;15:949-965.

25. Kawamoto A, Asahara T. Role of progenitor endothelial cells in cardiovascular disease and upcoming therapies. Catheter Cardiovasc Interv. 2007;70:477-484.
26. Lamichane S, Baek SH, Kim YJ, Park JH, Dahal Lamichane B, Jang WB, Ji S, Lee NK, Dehua L, Kim DY, Kang S, Seong HJ, Yun J, Lee DH, Moon HR, Chung HY, Kwon SM. MHY2233 attenuates replicative cellular senescence in human endothelial progenitor cells via SIRT1 signaling. Oxid Med Cell Longev. 2019;2019:6492029.

27. Incalza MA, D'Oria R, Natalicchio A, Perrini S, Laviola L, Giorgino F. Oxidative stress and reactive oxygen species in endothelial dysfunction associated with cardiovascular and metabolic diseases. Vascul Pharmacol. 2018;100:1-19. 